\title{
DESENHO MANUAL E TECNOLOGIAS DIGITAIS NA CRIAÇÃO DE ESTAMPAS
}

\author{
Janaina Ramos Marcos \\ Universidade do Estado de SantaCatarina \\ jana.ramosdesign@gmail.com \\ Neide Kohler Schulte \\ Universidade do Estado de Santa Catarina \\ neideschulte@gmail.com
}

\begin{abstract}
Resumo
Este artigo é resultado de projeto de extensão sobre design para estamparia realizado a partir de pesquisa exploratória em textos de artigos e de livros, e de conhecimento tácito desenvolvido na elaboração de materiais didáticos e nas aulas de Design de superfície e Design têxtil. O artigo apresenta o processo de criação de estampas, partindo de fontes de criatividade e do desenho manual, e finalizando-as com o uso de ferramentas de programas digitais para criação de rapport, padronagens e harmonias de cores. A criação de desenhos para estamparia com técnicas manuais e aperfeiçoamento com ferramentas digitais, utilizando processos de impressão, manuais ou industriais, agrega valor às superfícies têxteis. As padronagens, com motivos naturais, culturais, geométricos ou abstratos, introduzem nas superfícies têxteis efeitos decorativos cada vez mais personalizados através da combinação entre os desenhos manuais, o tratamento digital e a impressãodigital.
\end{abstract}

Palavras-chave: Estamparia. Desenho manual. Tratamento digital.

\section{MANUAL DRAWING AND DIGITAL TECHNOLOGIES IN THE MAKING OF PRINTS}

\begin{abstract}
This article is the result of extension project about printing design based on exploratory research in texts of articles and books, and of tacit knowledge developed in the elaboration of didactic materials and in the classes of Surface Design and Textile Design. The article presents the process of creating prints, starting from sources of creativity and manual drawing, and finalizing them with the use of digital software tools for creating rapport, patterns and color harmonies. The creation of designs for printing with manual techniques and improvement with digital tools, using printing processes, manual or industrial, adds value to the textile surfaces. Patterns, with natural, cultural, geometric or abstract motifs, introduce into textile surfaces decorative effects that are increasingly personalized through the combination of manual designs, digital processing and digital printing.
\end{abstract}

Keywords: Printing. Manual Drawing. Digital treatment.

\section{DISEÑO MANUAL Y TECNOLOGÍAS DIGITALES EN LA CREACIÓN DE ESTAMPAS}

\section{Resumen}

Este artículo es el resultado del proyecto de extensión sobre diseño para estampado realizado a partir de investigación exploratoria en textos de artículos y de libros, y de conocimiento tácito desarrollado en la elaboración de materiales didácticos y en las clases de Diseño de superficie y Diseño textil. El artículo presenta el proceso de creación de estampas, partiendo de fuentes de creatividad y del diseño manual, y finalizando con el uso de herramientas de programas digitales para la creación de rapport, patrones y armonías de colores. La creación de dibujos para estamparía con técnicas manuales y

Cidadania em Ação: Revista de Extensão e Cultura, Florianópolis (SC), v. 2, n.2, jul./dez. 2018. 
perfeccionamiento con herramientas digitales, utilizando procesos de impresión, manuales o industriales, agrega valor a las superficies textiles. Los patrones, con motivos naturales, culturales, geométricos o abstractos, introducen en las superficies textiles efectos decorativos cada vez más personalizados a través de la combinación entre los diseños manuales, el tratamiento digital y la huella digital.

Palabras clave: Estampación. Dibujo manual. Tratamiento digital. 


\section{INTRODUÇÃO}

Estamparia é a impressão de desenhos em tecidos, malhas e em outros materiais, com técnicas manuais ou industriais, com o objetivo de aplicar na superfície efeitos decorativos. A estamparia agrega valor às superfícies têxteis e, segundo historiadores, teve seu início com as inscrições rupestres do período Paleolítico, que são considerados os primeiros registros de impressão de um padrão.

Entre os historiadores há divergências sobre o primeiro povo que estampou em tecidos. Há registros que indicam os povos egípcios, fenícios, persas e indianos como sendo os primeiros que produziram tecidos estampados, que eram feitos com técnicas manuais como carimbos e estêncil, e alguns com aplicação de bordados. Para estampar e tingir eram utilizados corantes e fixadores naturais extraídos de plantas (sementes, caules, raízes, folhas), cinzas e alguns minerais.

A serigrafia, a termo-impressão e a impressão digital são as principais técnicas utilizadas atualmente nos processos de estamparia em tecidos, e para criação das estampas são utilizadas técnicas manuais de desenho e pintura associadas a ferramentas digitais.

A partir de pesquisa exploratória em textos de artigos e de livros, e do conhecimento tácito desenvolvido nas aulas de Design de superfície e Design têxtil, este artigo apresenta o processo de criação de estampas partindo do desenho manual e de ferramentas de programas digitais.

\section{A ESTAMPARIA NO DESIGN TÊXTIL}

O design têxtil é considerado uma especialização do design de superfície, que abrange desde a composição do tecido até a estamparia. Ou seja, atua desde a criação de novas tramas, padronagens dos fios, dos tecidos, até o tingimento e impressão de estampas sobre os mesmos.

Os profissionais que atuam no design têxtil caracterizam-se por propor novas e criativas combinações, como também pela capacidade de "criar um produto de qualidade estética e funcional a partir do redesenho ou transformação deprodutos desenvolvidos originalmente para servirem funções" (COSTA, 2003). Portanto, o design têxtil faz uso da atividade projetual, de forma a sintonizar a criatividade com a viabilidade.

Na criação de uma coleção para estamparia, tanto no processo de planejamento e de programação do projeto, como na concepção do produto, "os processos criativos, os métodos e as técnicas de desenvolvimento do produto dominam atividades no período em que o 
produto é gerado" (COSTA, 2003). Segundo a autora, como em qualquer projeto, é composto por algumas etapas, como: (1) definição do problema, (2) análise do problema, (3) síntese, (4) avaliação e (5) desenvolvimento. Assim, cabe ao designer têxtil analisar o mercado, pesquisar sobre os desejos e necessidade do consumidor com o objetivo de criar produtos que agreguem valor.

Para atender as necessidades do homem contemporâneo, houve uma grande expansão da tecnologia no setor do design têxtil. Os designers precisam se adequar às inovações em termos de criação, apresentando produtos mais criativos e considerando cada vez mais os impactos socioambientais da indústria têxtil em toda cadeia produtiva.

Com o avanço da tecnologia as técnicas artesanais foram perdendo espaço. De acordo com Vincent-Ricard (1987d) “[...] a propagação da informática resultou na preocupação do desaparecimento do artesanato. Essa inquietação fez surgir na sociedade uma assimilação inovadora entre as tecnologias de ponta e os conhecimentos artesanais".

$\mathrm{Na}$ criação de motivos para as padronagens usadas na estamparia, por exemplo, tem sido valorizado o uso de técnicas manuais de desenho, pintura, aquarelas, colagens, entre outras técnicas, bem como o uso de técnicas artesanais de estamparia e tingimento como carimbos, estêncil, batik e tie-dye, que são digitalizados e retrabalhados com tratamentos digitais.

\section{MOTIVOS E PADRÕES NA ESTAMPARIA}

A partir das imagens encontradas sobre tecidos ao longo da história, Edwards (2012), divide os temas mais recorrentes em natural, floral, animal, estilizado, geométrico, abstrato, figurativos, objetos, grades, listras e figuras humanas.

$\mathrm{Na}$ estamparia o tema natural, que se refere aos padrões que tem a natureza como fonte de inspiração, mais especificamente a flora através da representação de flores, folhas, árvores, plantas e frutas, foi o tipo de representação mais utilizado durante a história nos motivos para as padronagens impressas nas superfícies têxteis.

Os florais eram os motivos predominantes na Índia, e foram levados para a Europa em torno de 1640. O floral foi o motivo predominante até o fim do século XVIII. No final do século XIX voltou a predominar com o movimento artístico Art Noveau (PEZZOLO, 2009) e continua como um motivo recorrente na estamparia atual. Os motivos florais são representados de diversas formas: grandes, pequenas, misturadas a outros elementos ou isoladas, fotografadas ou estilizadas como exemplo na Figura 1.

Cidadania em Ação: Revista de Extensão e Cultura, Florianópolis (SC), v. 2, n.2, jul./dez. 2018. 
Figura 1: Floral estilizado

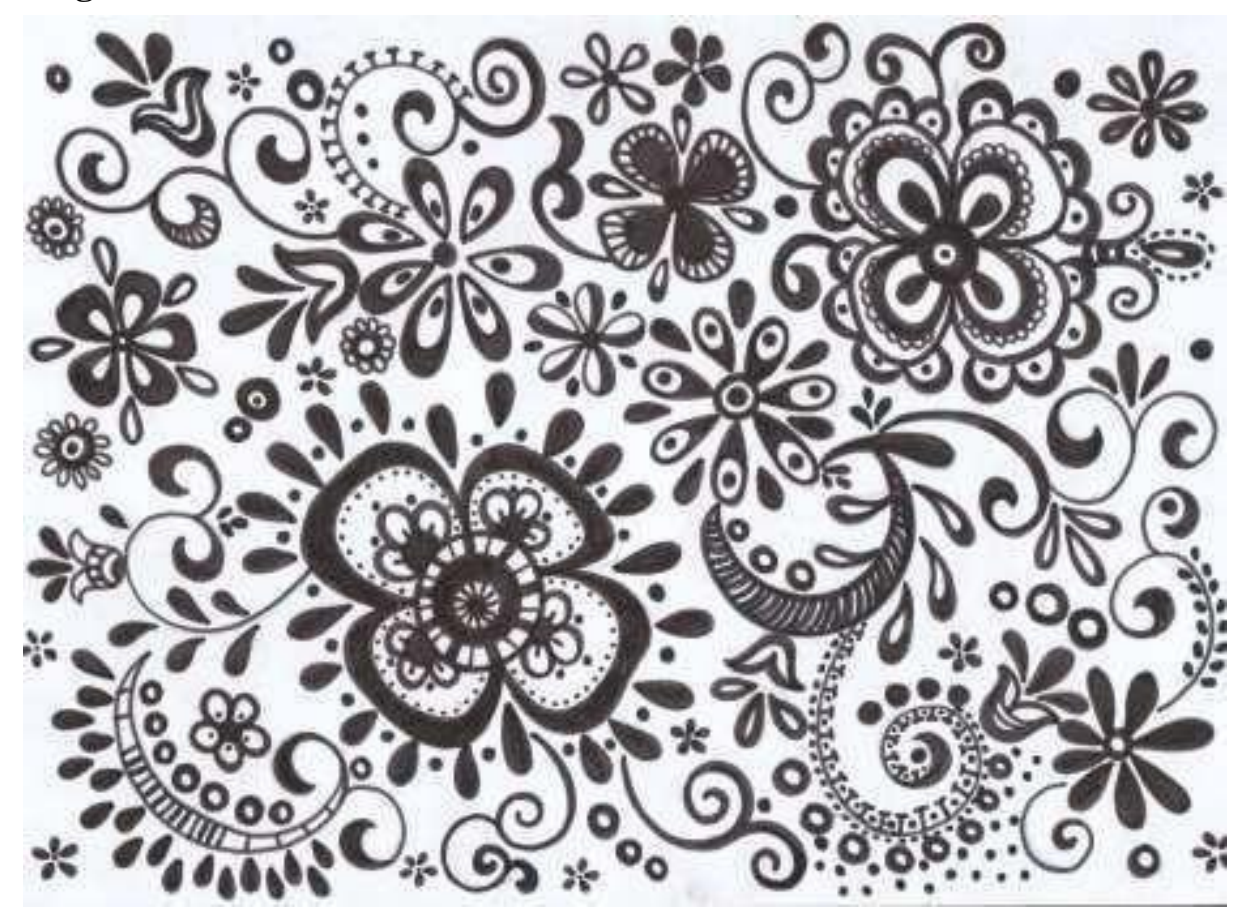

Fonte: Acervo pessoal (2016).

Motivos inspirados em animais também são muito utilizados na criação de estampas e fazem parte da história da estamparia. A pele de animais e a plumagem das aves foram usadas como inspiração para estampar em tecidos há mais de 5 mil anos, de acordo com registros históricos (PEZZOLO, 2009). A representação da fauna (garças, pavões, cavalos e elefantes) - em algumas culturas - está associada a superstições, crenças e simbolismos (EDWARDS, 2012). Diversos tipos de animais são utilizados em representações gráficas visuais para criar motivos: borboletas, animais marinhos, pássaros, entre outros. As estampas com motivos felinos, exemplificado na Figura 2, são usadas com frequência e aparecem em peças do vestuário e tecidos para decoração.

Cidadania em Ação: Revista de Extensão e Cultura, Florianópolis (SC), v. 2, n.2, jul./dez. 2018. 
Figura 2: Felino estilizado

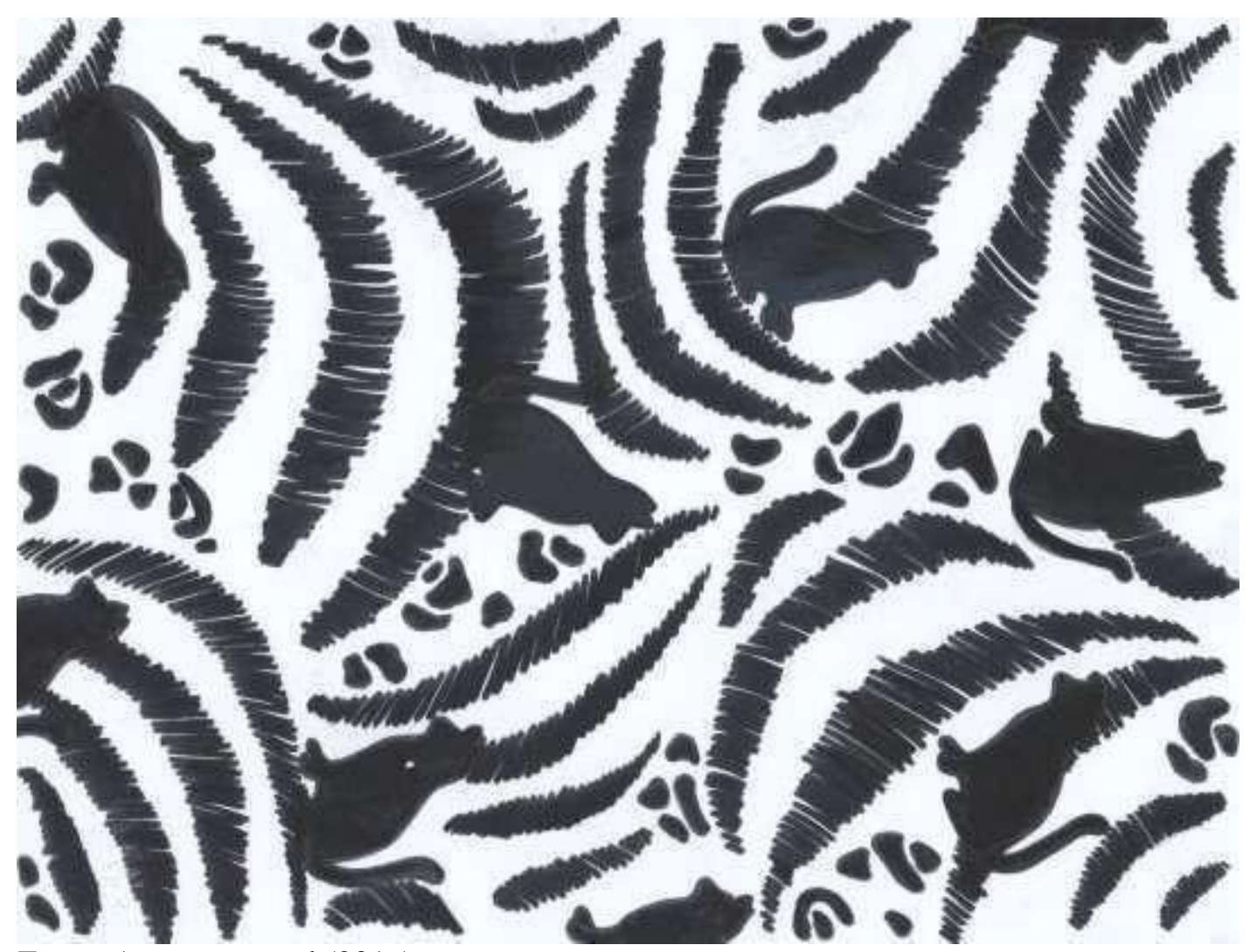

Fonte: Acervo pessoal (2016).

A estilização é um conjunto de formas artísticas que são utilizadas pelos designers têxteis para criar efeitos singulares e reconhecíveis, naturais ou espontâneos, para apresentar uma ideia convencional ou adaptação de uma para representação de motivos. As formas geométricas são um tipo de estilização também muito usado na estamparia. No século XX foram muito valorizadas, impulsionadas pelo movimento Art Deco. Os xadrezes, listrados, e poás são motivos geométricos clássicos que se mantém na moda. A estilização permite que um desenho seja planejado com repetições simétricas e ordenadas mas, pode ser representado também sem simetria, conforme exemplo na Figura 3.

Cidadania em Ação: Revista de Extensão e Cultura, Florianópolis (SC), v. 2, n.2, jul./dez. 2018. 


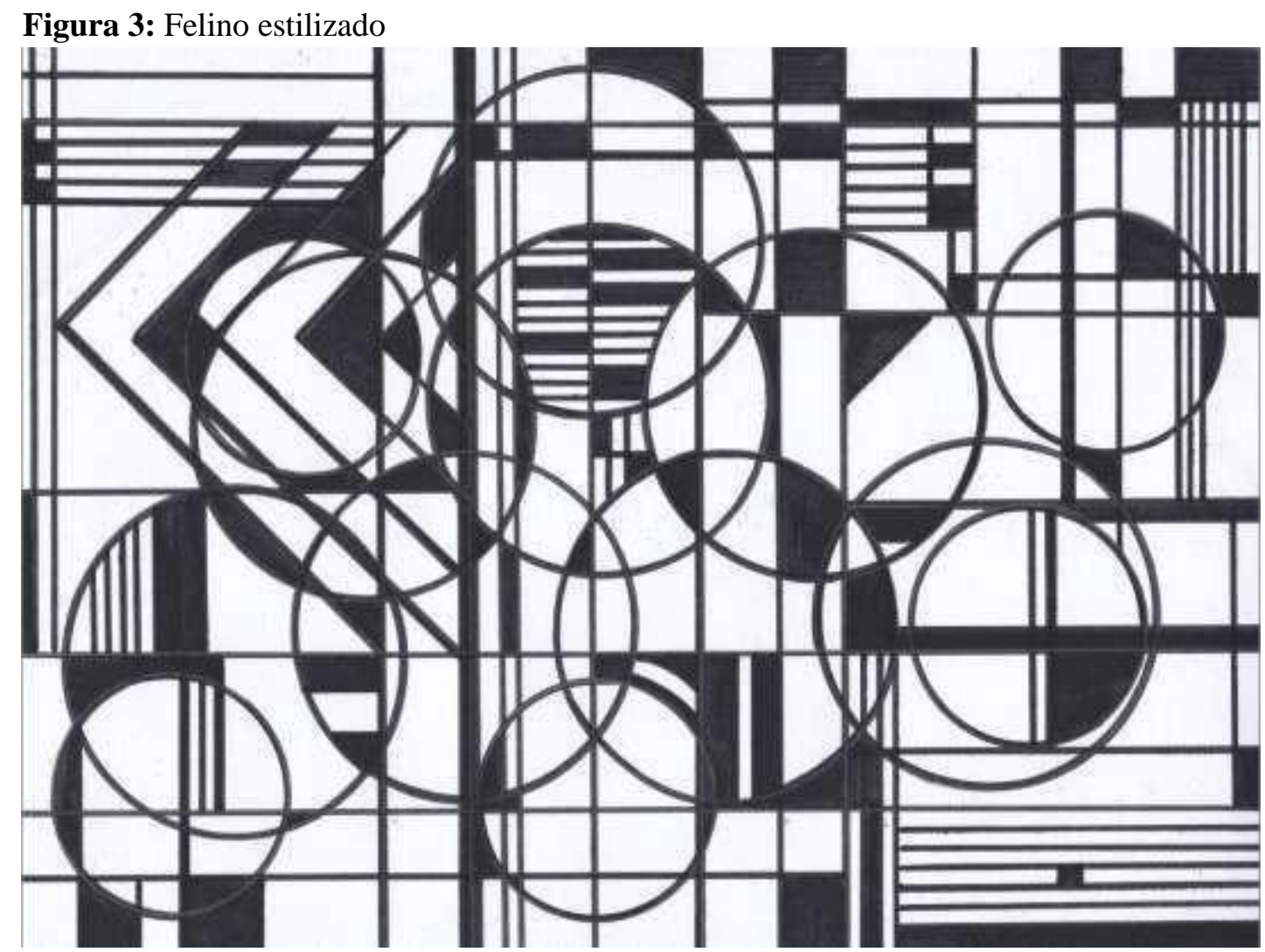

Fonte: Acervo pessoal (2016).

\section{Criação de motivos, módulos, padrões e sistemas de repetição}

Para criação de motivos existem várias técnicas e fontes para criatividade. Segundo Castro (1981), as principais fontes para criatividade são: a natural, a cultural, a geométrica e a individual. A fonte natural usa como inspiração os elementos da natureza: animais, plantas e minerais. A fonte cultural se inspira nas criações humanas: obras de arte, arquitetura, artesanato, entre outras. A fonte geométrica usa as formas básicas da geometria como círculos, quadrados, triângulos e outras formas estilizadas. Na fonte individual o desenhista se inspira nas preferências pessoais, que diferem de um designer para outro.

A partir da fotografia de uma orquídea, Figura 4, uma fonte natural para criatividade, criou-se motivos para estamparia conforme exercício ilustrado, Figura 5 que consistiu em três etapas: fazer um desenho de observação, um estilizado e um abstraído.

Cidadania em Ação: Revista de Extensão e Cultura, Florianópolis (SC), v. 2, n.2, jul./dez. 2018. 
Figura 4: Fotografia da orquídea.

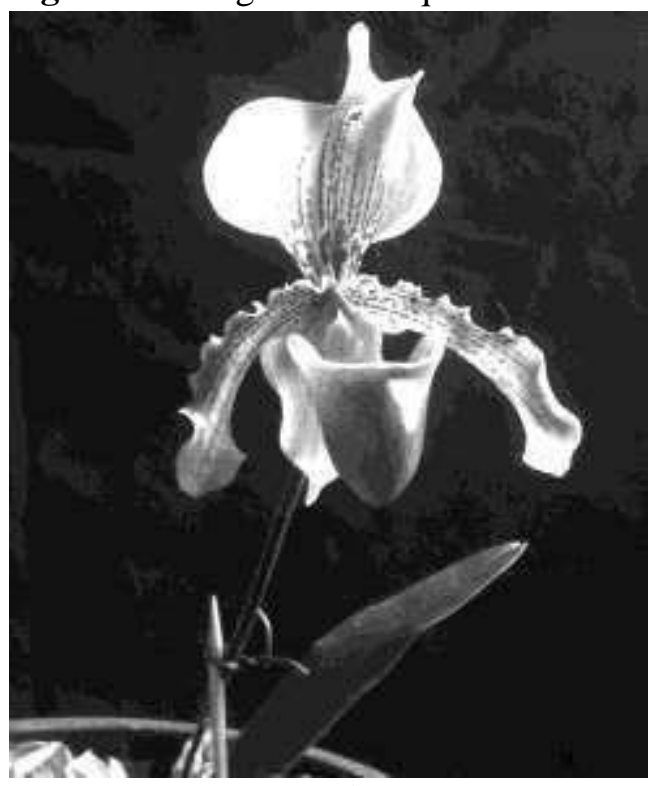

Fonte: Acervo pessoal (2016).

A primeira etapa do exercício é o desenho de observação, partindo-se da observação dos objetos, neste caso da orquídea. Para realizar-se o desenho de observação deve-se enquadrar o desenho no quadro usando uma linha horizontal e outra vertical para encontrar o centro da fotografia, estas linhas servirão de referência para seu enquadramento. A segunda etapa é a estilização, desenho com traços simplificados, partindo-se da base e da estrutura do primeiro desenho. A terceira etapa é a criação de um desenho a partir das estruturas do segundo desenho, porém trata-se de um desenho abstrato, ou abstração das formas do desenho original, ou seja, esse desenho pode parecer diferente dos objetos desenhados anteriores. Trata-se de uma modificação usando formas abstratas para representar os objetos. As três etapas podem observadas na Figura 5.

Cidadania em Ação: Revista de Extensão e Cultura, Florianópolis (SC), v. 2, n.2, jul./dez. 2018. 
Figura 5: Desenho de observação, estilização e abstração da orquídea.

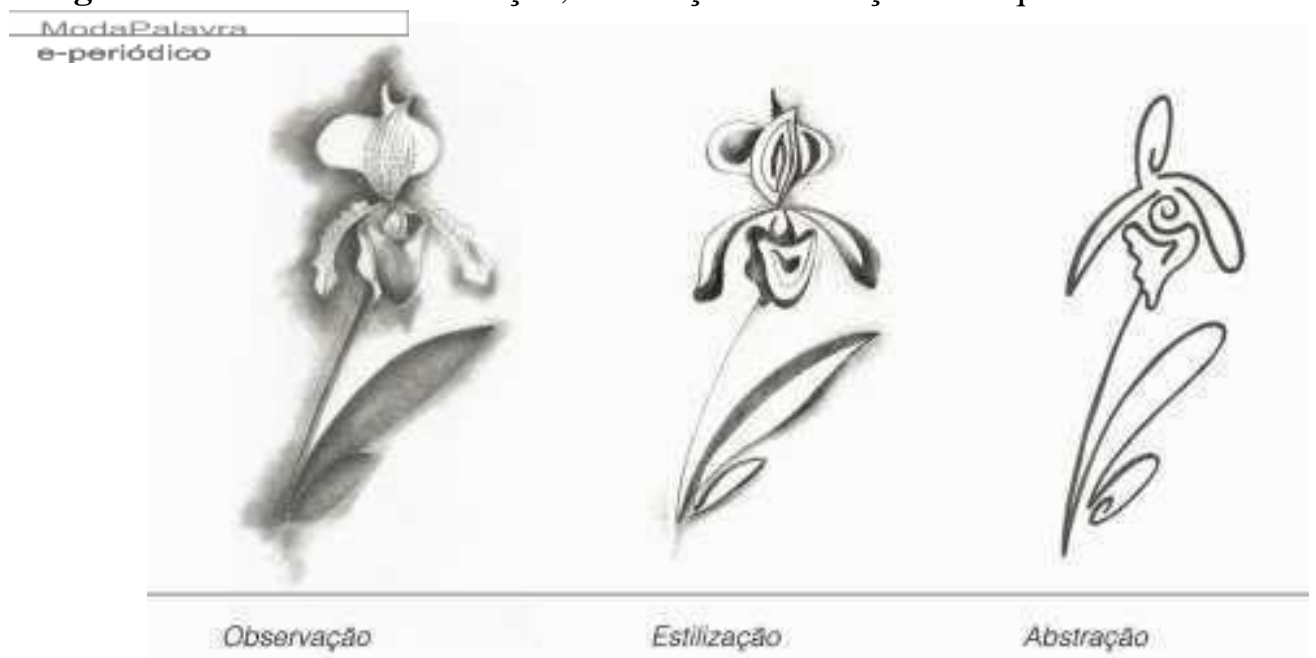

Fonte: Acervo pessoal (2016).

Os desenhos criados a partir dessa técnica podem ser usados como motivos para formar padrões em rapport para padronagens em projetos de design de estampas. A fotografia da orquídea também pode ser utilizada como motivo em estampas para impressão digital. Para se iniciar um projeto de design de superfície, uma coleção de estampas, por exemplo, há muitos aspectos a serem considerados pelo designer e a composição visual é um dos principais, independentemente da metodologia utilizada.

Na criação de elementos visuais para estamparia, a maneira como eles são distribuídos sobre o fundo é fundamental para a qualidade estética do trabalho. A sintaxe visual do design de superfícies identifica funções de elementos visuais como: as figuras ou motivos, os elementos de preenchimento e os elementos de ritmo (RÜTHSCHILLING, 2008).

As figuras ou motivos são formas contínuas que aparecem repetidamente em primeiro plano na composição, apresentando variações de formas e tamanhos, e conferem o sentido ou o tema da mensagem visual da composição. Os elementos de preenchimento são grafismos e texturas que preenchem o plano de fundo e fazem a ligação visual entre os elementos da composição.

Os elementos de ritmo são responsáveis pela propagação visual, que é obtida pela configuração, pela posição, pelas cores, entre outros aspectos conferidos aos elementos na composição. Nos elementos de ritmo, a continuidade é a sequência ordenada e ininterrupta de efeitos visuais garantindo o efeito de propagação, e a contiguidade é a repetição dos módulos lado a lado e de cima para baixo, formando um padrão.

Na metodologia projetual para o design de superfície e também, mais especificamente

Cidadania em Ação: Revista de Extensão e Cultura, Florianópolis (SC), v. 2, n.2, jul./dez. 2018. 
para criação de estampas, se indica caminhos a serem seguidos na criação: o módulo e sua construção, o encaixe dos motivos entre os módulos, a repetição dos módulos, sistema de repetição dos módulos e multimódulos.

O módulo é a menor área que inclui todos os elementos visuais que constituem o desenho de uma padronagem. A sua composição visual depende da organização dos motivos dentro do módulo e da articulação entre os módulos, gerando o padrão.

O encaixe é o estudo feito prevendo-se os pontos de encontros das formas entre um módulo e outro de maneira que, quando justapostos, se forma o desenho contínuo. A noção de encaixe é regida pela continuidade e contiguidade. Continuidade é a sequência ordenada e ininterrupta de elementos visuais dispostos sobre uma superfície, garantindo o efeito de propagação. Contiguidade é a harmonia visual na vizinhança dos módulos, estado de união visual. De modo que, quando repetidos lado a lado e em cima e embaixo, os módulos formem um padrão.

A repetição dos módulos, formando o rapport, é feita com a colocação dos módulos nos dois sentidos, comprimento e largura, de modo contínuo, configurando o padrão. E o sistema de repetição é a lógica adotada para a repetição. Existe uma grande variedade de possibilidades de repetição dos módulos que pode ser através de sistemas alinhados (translação, rotação, reflexão) Figura 6, de sistemas não alinhados, de sistemas progressivos, por multimódulo e através de composições sem encaixe.

Figura 6: Motivos em sistemas alinhados (translação, rotação, reflexão).

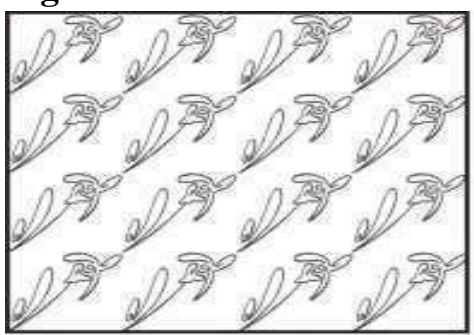

ROTAÇÃO

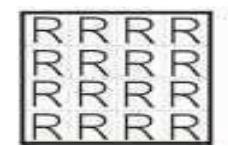

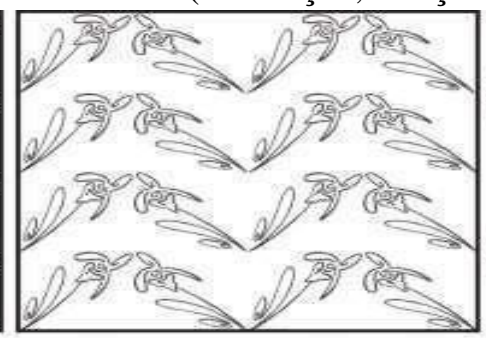

TRANSLAÇÃO

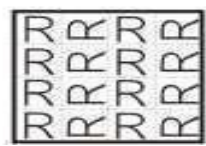

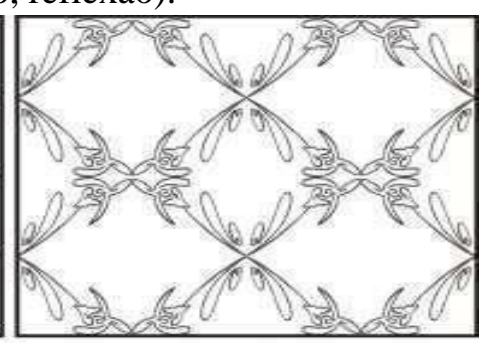

REFLEXĀO

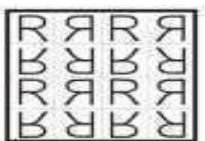

Fonte: Acervo pessoal (2016).

Em sistemas alinhados, o módulo pode ser movimentado nas células através de rotação, translação e reflexão. Na rotação, o módulo mantém a direção e desloca-se sobre um eixo, na translação o deslocamento do módulo é radial e, na reflexão, ele é espelhado em relação ao eixo.

Nos sistemas não alinhados são determinadas medidas ou porcentagens para o Cidadania em Ação: Revista de Extensão e Cultura, Florianópolis (SC), v. 2, n.2, jul./dez. 2018. 
deslocamento das células para colocação dos módulos, e pode-se usar as mesmas possibilidades de operação dos sistemas alinhados, tornando mais complexa a estrutura da composição. Na Figura 7 apresenta-se exemplo de repetição de motivos em sistemas não alinhados.

Figura 7: Motivos em sistemas não alinhados.

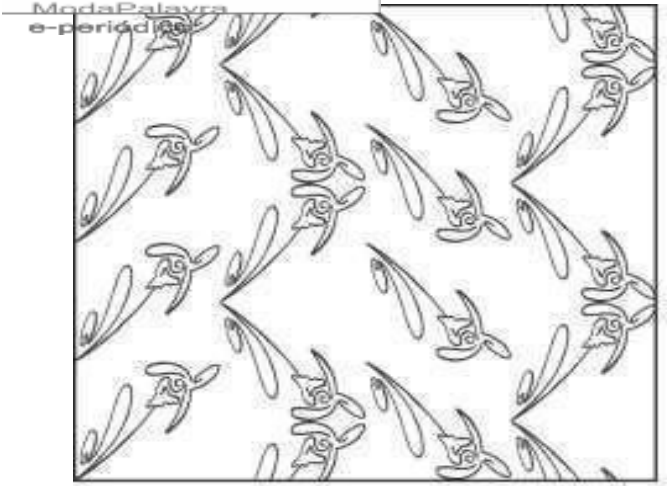

Deslocamento horizontal

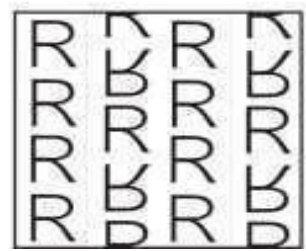

Fonte: Acervo pessoal (2016).

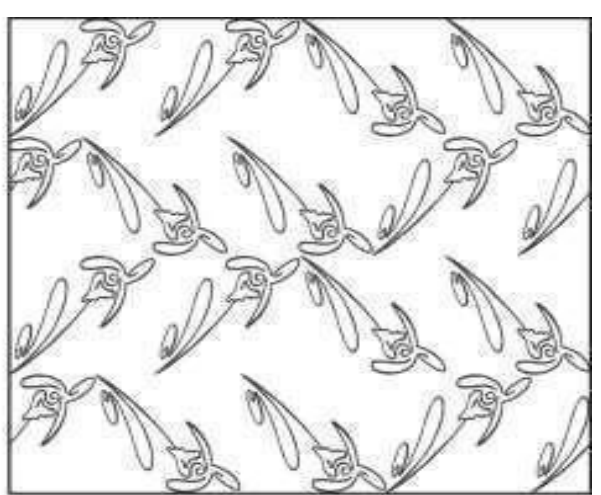

Deslocamento vertical

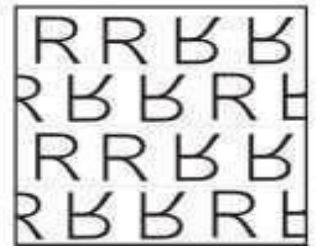

Nas repetições com sistemas progressivos, há uma mudança gradual do tamanho das células, ampliando ou reduzindo, de acordo comum a lógica de expansão que é determinada. Nas obras do artista gráfico holandês Escher encontra-se muitos exemplos de repetições com sistemas progressivos, um deles está na Figura 8.

Figura 8: Motivos em sistemas não alinhados.

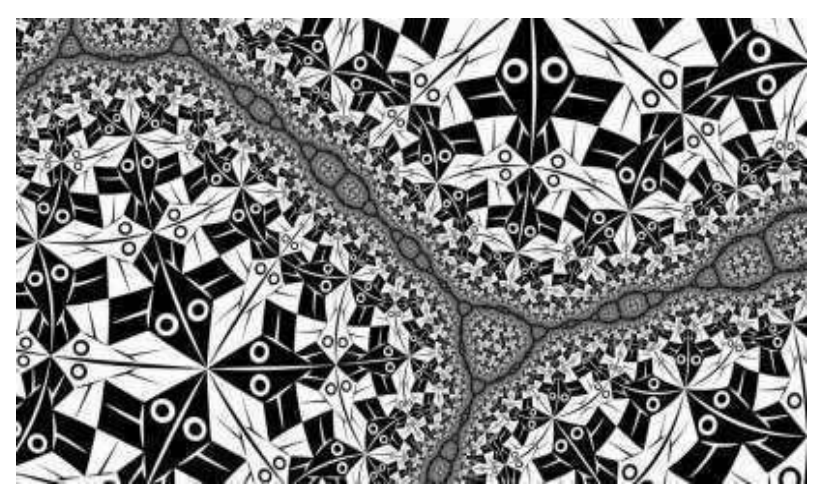

Fonte: TJABBES, Pieter. O mundo mágico de ESCHER, 2011.

Os multi módulos são sistemas formados por módulos menores que são repetidos e agrupados, passando a funcionar como um módulo, aumentando as possibilidades de repetição, formando diferentes desenhos. Imagens também podem funcionar como multi módulos.

Cidadania em Ação: Revista de Extensão e Cultura, Florianópolis (SC), v. 2, n.2, jul./dez. 2018. 
As composições sem encaixe dispensam as noções clássicas de módulo, não há continuidade formal, mas sim pelas texturas, configurações externas, equilíbrio de cores e elementos. São módulos que não se encaixam, pois as composições internas dos módulos são diferentes, mas mantém uma fluência visual.

\section{Criação de rapport para formação de padronagens}

O rapport se forma com a repetição dos módulos, que são colocados nos dois sentidos, comprimento e largura, de modo contínuo, configurando o padrão, de acordo com o sistema de repetição adotado. Na padronagem da estampa não há início nem fim, como se não houvesse emenda dos desenhos. É uma técnica usada para estamparia corrida, com quadros ou cilindros, sendo que o tamanho do rapport é determinado pelo método de impressão.

A criação do rapport pode ser realizada a partir de desenho manual ou digital. No desenho manual, uma técnica que pode ser utilizada consiste em fazer um desenho mais centralizado num quadrado (rapport). Depois corta-se o quadrado no centro, numa linha horizontal e vertical. As quatro partes do desenho que estava centralizado são colocadas nos cantos, como um quebra-cabeça, e o centro do quadrado, que ficou vazio, é preenchido com mais motivos ou outros elementos de preenchimento como texturas, linhas, etc., conforme ilustra a Figura 9.

Figura 9: Rapport manual.
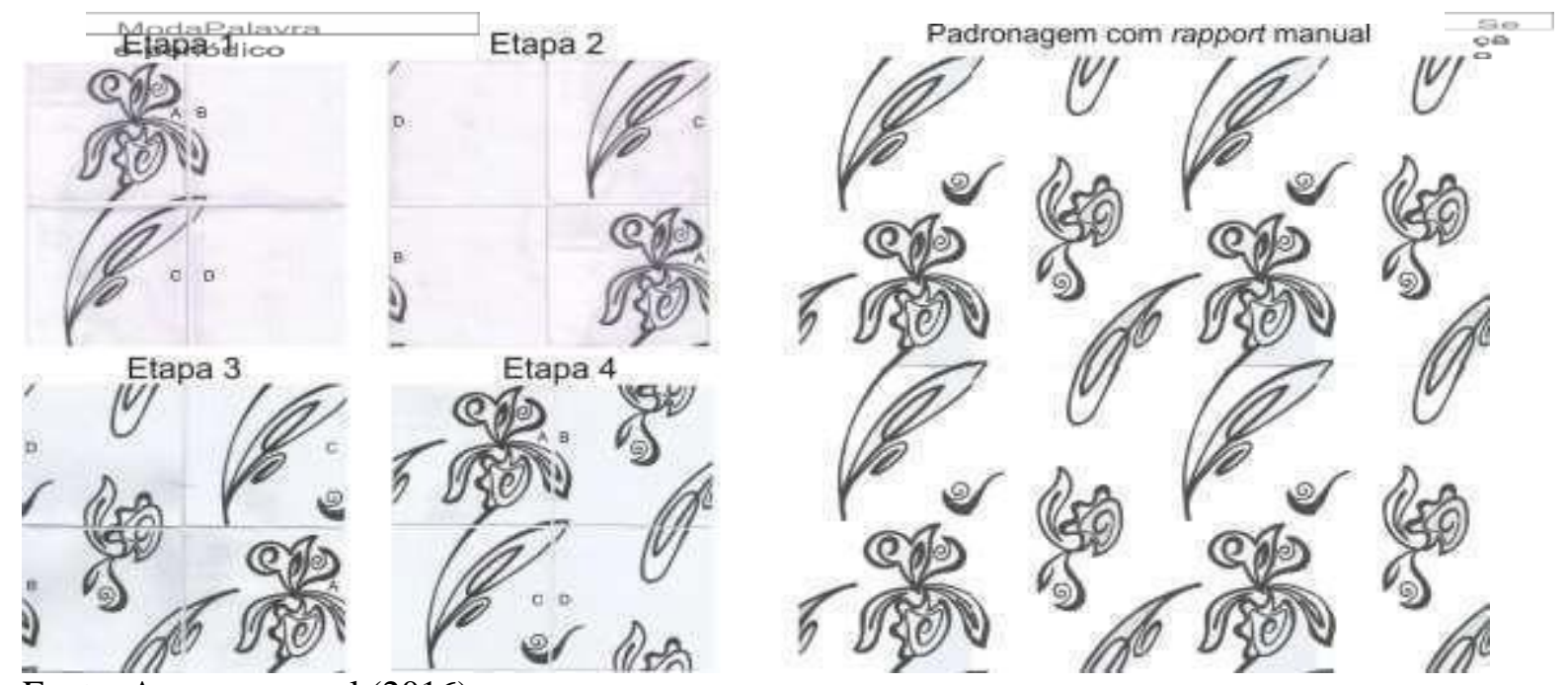

Fonte: Acervo pessoal (2016).

Cidadania em Ação: Revista de Extensão e Cultura, Florianópolis (SC), v. 2, n.2, jul./dez. 2018. 


\section{FERRAMENTAS DIGITAIS DE NA CRIAÇÃO RAPPORT E NA HAMONIA DE CORES}

Um rapport pode ser criado com ferramentas digitais utilizando-se, para isso, softwares de computação gráfica, como o Illustrator® e o Photoshop®, por exemplo.

O Illustrator® é um programa de desenho vetorial, ou seja, para composição de desenhos que se utilizam de primitivas geométricas, como o ponto, a linha e o plano. Já o Photoshop® é um software voltado para manipulação de imagens, utilizando para isso a edição de pixels. O pixel é a menor unidade que compõe a imagem digital.

Para criação de padronagens e construção de rapport, nesse software, existem duas maneiras: uma automática, onde o próprio Illustrator define o sistema de repetição a ser adotado e uma manual, onde pode-se construir sistemas alinhados, não alinhados e estampas corridas. A Figura 10 representa a criação de um módulo (ou motivo) no Illustrator e a aplicação da técnica automática de construção de padronagem, utilizando o sistema chamado Brick by Column ou "tijolinho por coluna".

Figura 10: Rapport digital com sistema automático Illustrator®.

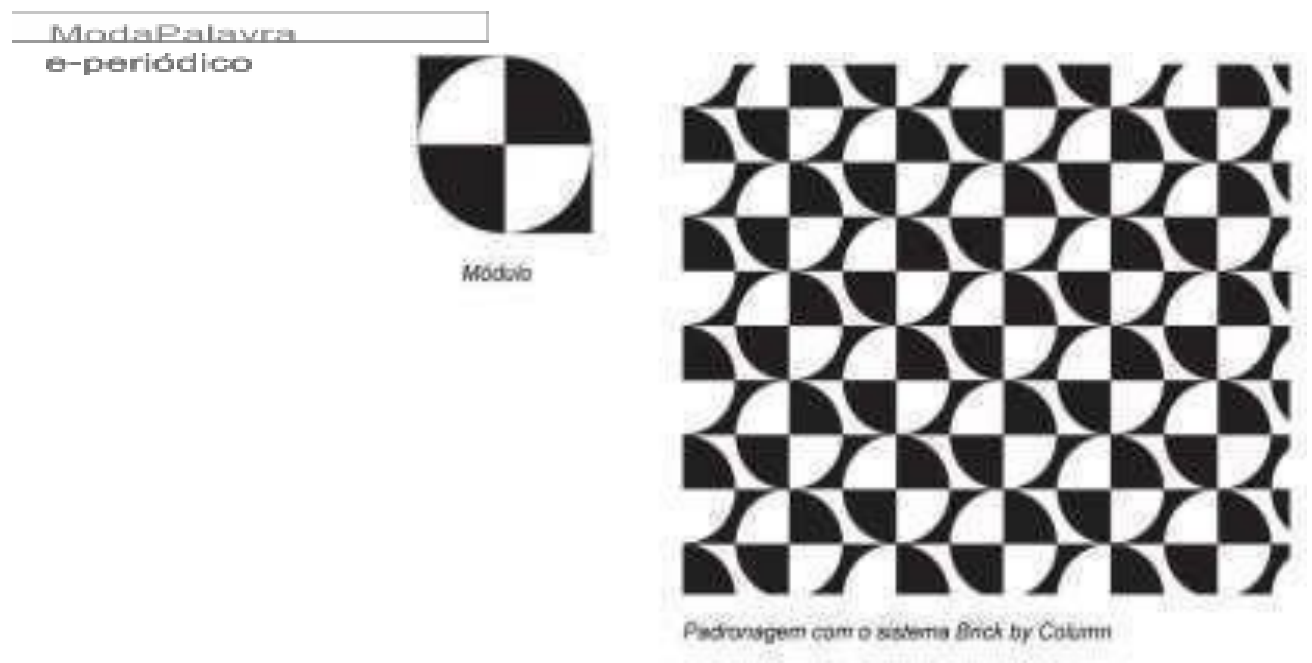

Fonte: Acervo pessoal (2016).

A figura acima mostra a construção de uma padronagem geométrica, inspirada na obra do artista plástico Athos Bulcão. O artista foi convidado por Oscar Niemeyer para "decorar" Brasília e hoje podemos observar seu trabalho em vários prédios governamentais da capital do Brasil. Outra forma de construção de estampas e padronagens no Illustrator é através do método manual, mais utilizada para estampas corridas, onde se constrói um arquivo com encaixe perfeito.

Cidadania em Ação: Revista de Extensão e Cultura, Florianópolis (SC), v. 2, n.2, jul./dez. 2018. 
Figura 11: Rapport digital com sistema manual para estampa corrida, Illustrator®.
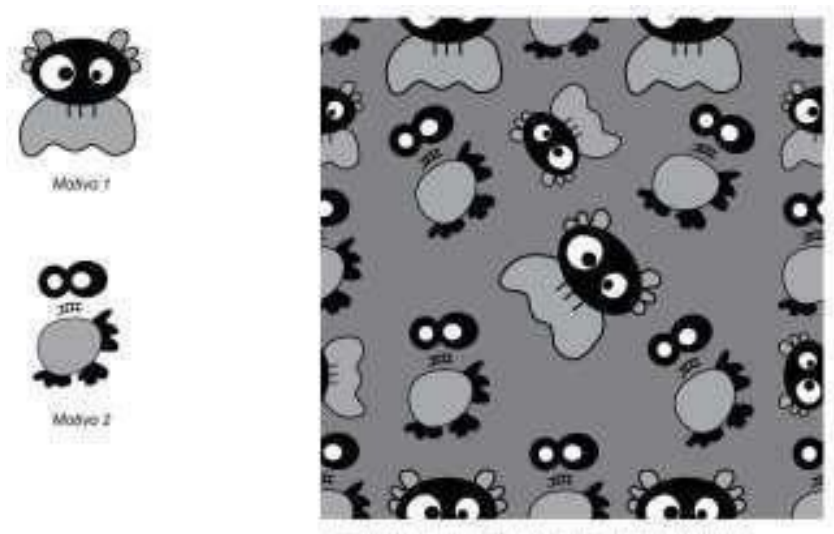

Fonte: Acervo pessoal (2016).

A figura acima mostra a construção de um rapport para estampa corrida, com encaixes perfeitos. O sistema aplicado foi o manual, com uma técnica onde é definido um arquivo do tamanho do rapport $(16 \times 16,32 \times 32$ ou $64 \times 64 \mathrm{~cm})$ e os elementos são posicionados à direita e à esquerda, no topo e abaixo, configurando o encaixe, deixando a parte central com área para livre posicionamento dos motivos.

Esses podem ser rotacionados ou espelhados de forma a construir uma composição ideal. Os motivos aplicados foram primeiramente desenhados à mão e retraçados no Illustrator® e transformados em desenho vetorial.

Como citado anteriormente, o Photoshop ${ }^{\circledR}$ é um software para manipulação de imagens. Aqui, as imagens também podem ser transformadas em padronagens e rapports, com alto grau de complexidade, mas com grande facilidade de construção. As padronagens podem ser construídas a partir de recortes de imagens figurativas (flores, pássaros, etc...), utilizando partes de imagens e, ainda, construídas com desenhos manuais escaneados e "tratados" digitalmente.

Para construção de rapports digitais no Photoshop ${ }^{\circledR}$ existem várias técnicas, uma delas chama-se Repetição em Bloco com Offset Filter (BRIGGS- GOODE,2014). Essa técnica pode ser utilizada tanto para módulos com motivos digitais, como para motivos desenhados manualmente. Observe exemplos desses rapports nas Figuras 12 e 13.

Cidadania em Ação: Revista de Extensão e Cultura, Florianópolis (SC), v. 2, n.2, jul./dez. 2018. 
Figura 12: Rapport digital com imagens recortadas para estampa corrida, Photoshop®.

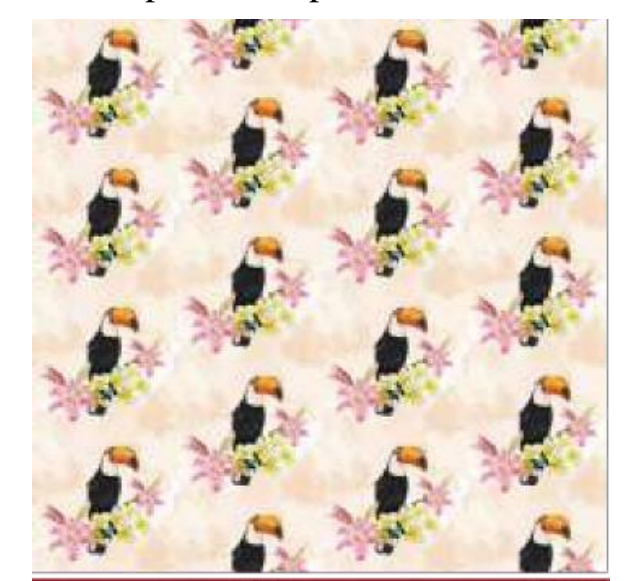

Fonte: Acervo pessoal (Janaina Ramos, 2016).
Figura 13: Rapport digital com desenhos manuais, Photoshop®.

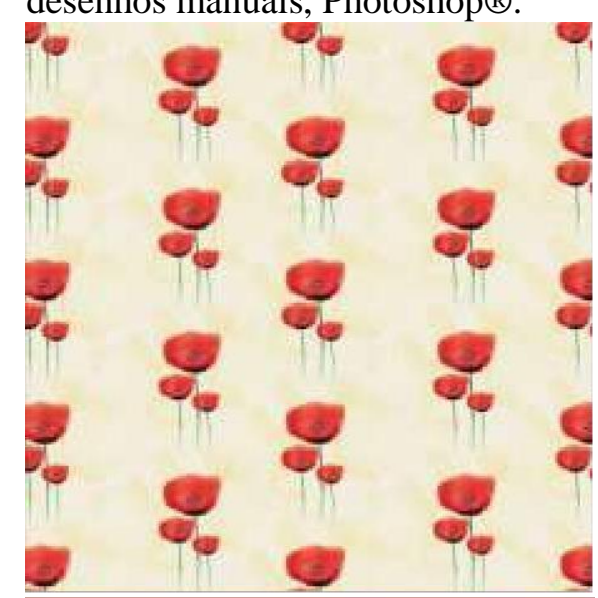

Fonte: Acervo pessoal (Janaina Ramos, 2016)

Na Figura 12, os elementos foram extraídos de imagens e recortados através de técnicas do Photoshop. A Figura 13 demonstra a mesma técnica de construção de rapport Repetição em Bloco com Offset Filter aplicada a um motivo floral desenhado manualmente, com tratamanento de imagem no Photoshop® e utilização de fundo com bruhes (pincéis) de aquarela, criados digitalmente e disponíveis para download na internet.

Uma parte de uma imagem, sem o emprego de recortes, também pode se transformar em estampas criativas e exclusivas. A técnica usada é chamada de rapport com módulos iguais e seu resultado é uma padronagem extremamente rica em detalhes e elementos. Observe a Figura 14, uma imagem que foi feita em uma floricultura com o auxílio de câmera de smartphone. Observe a Figura 15, onde o rapport foi criado com a técnica de módulos iguais, espelhados e rotacionados. Foi aplicado ainda filtro de cores e modos de mistura, obtendo-se um efeito exclusivo, semelhante a um fractal.

Cidadania em Ação: Revista de Extensão e Cultura, Florianópolis (SC), v. 2, n.2, jul./dez. 2018. 
Figura 14: Imagem de flores feitas com smartphone

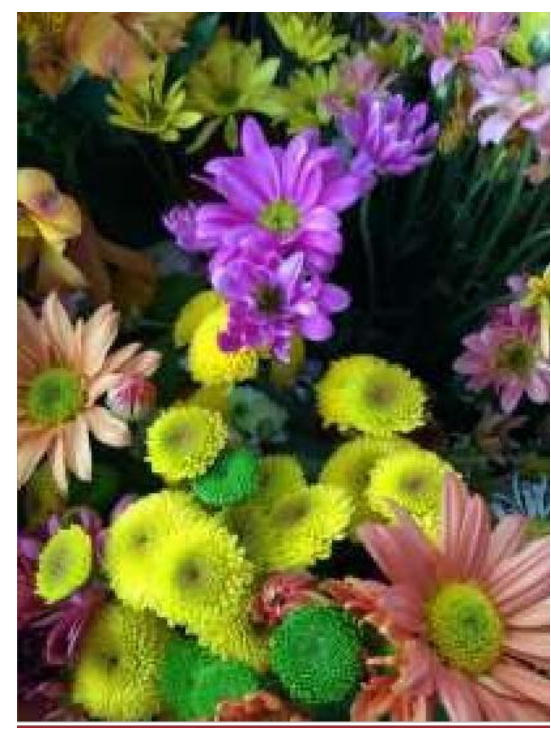

Fonte: Acervo pessoal (2016)
Figura 15: Rapport criado com imagem feita com smartphone

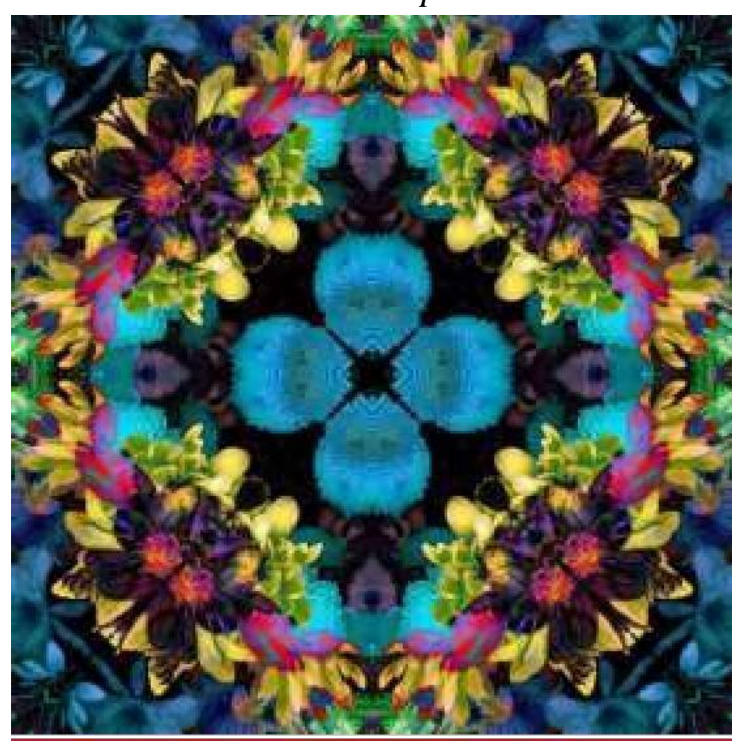

Fonte: Acervo pessoal (2016)

Percebe-se que o desenvolvimento de padronagens e motivos, tanto com o Illustrator ${ }^{\circledR}$ quanto com o Photoshop®, possui uma ilimitada possibilidade criativa, permitindo, por exemplo, a mistura de geométricos com florais onde figurativos podem se transformar em abstratos.

No Illustrator ${ }^{\circledR}$, pode-se ainda realizar complexos estudos de cores no rapport, criando uma variada gama de estampas diferentes, inclusive com harmonia de cores.

A cor possui força para transformar um desenho de categoria inferior em excelente trabalho, assim como pode ter efeito destrutivo num trabalho muito bem concebido. A cor é critério, pois ela carrega, em sua tonalidade, infinitas percepções: cultural, individual, regional ou religiosa, as cores imprimem sensações, impregnadas de subjetivismo (RUBIM, 2011).

A harmonia das cores é, portanto, subjetiva. Variáveis culturais e pessoais, entre outras, contribuem para a interpretação das cores. A harmonia está associada a uma lógica interna das relações entre os elementos de uma composição e as cores. Portanto, a harmonia de cores é complexa e sutil, pois as cores funcionam em conjunto. Não há um valor absoluto para cada cor, o que importa é o conjunto.

A adequação das cores define a harmonia. Uma estampa com a harmonia de cores quentes, por exemplo, pode agradar um determinado consumidor, mas, se for modificada a variante, com outra harmonia, ela poderá não agradar.

$\mathrm{Na}$ estamparia são usadas harmonias cromáticas, monocromáticas, análogas, complementares, quentes, frias e neutralizadas. A Figura 16 apresenta uma estampa manual com quatro variantes de harmonias.

Cidadania em Ação: Revista de Extensão e Cultura, Florianópolis (SC), v. 2, n.2, jun./dez. 2018. 
Figura 16: Estampa manual com quatro variantes de harmonias de cores.
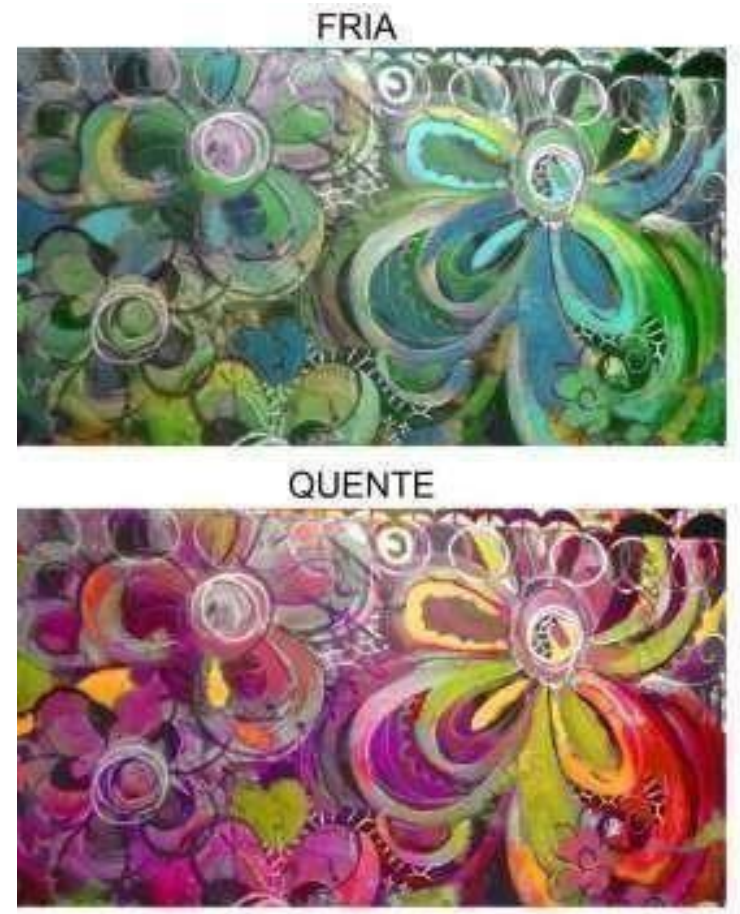

Fonte: Acervo pessoal (Isabel Possidônio; Neide Schulte, 2016).
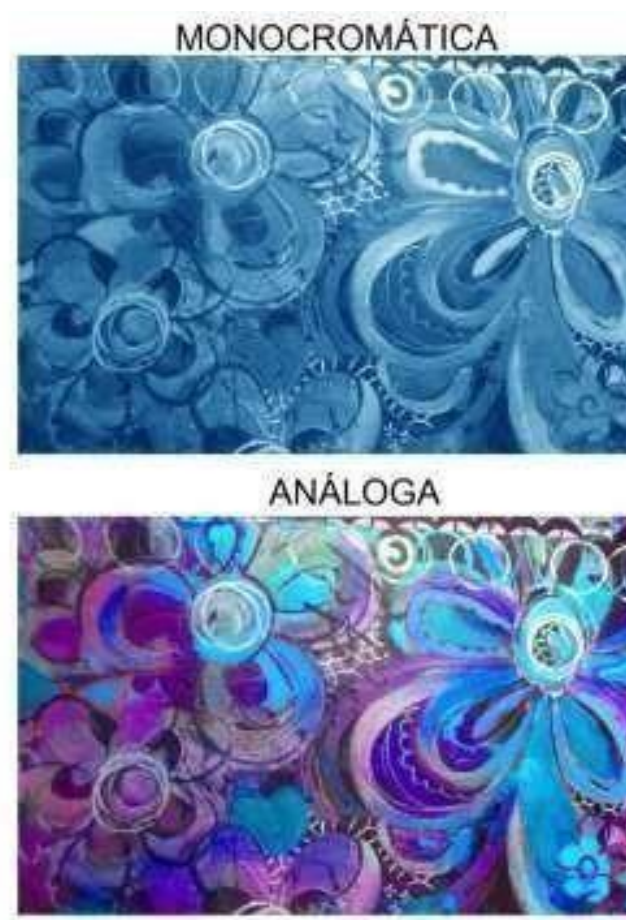

\section{CONSIDERAÇÕES FINAIS}

A estamparia, através da criação de desenhos com técnicas manuais e aperfeiçoamento com ferramentas digitais, utilizando processos de impressão, manuais ou industriais, agrega valor às superfícies têxteis. As padronagens, com ou sem sistemas de repetições de módulos e rapport, com motivos naturais, culturais, geométricos ou abstratos, com variantes nas harmonias de cores, introduzem nas superfícies têxteis efeitos decorativos cada vez mais personalizados através da combinação entre os desenhos manuais, o tratamento digital e a impressão digital. Dos primeiros padrões representados nas cavernas às estampas digitais, a estamparia, através de linhas, formas, texturas, composições e cores expressa o espírito de cada época.

Cidadania em Ação: Revista de Extensão e Cultura, Florianópolis (SC), v. 2, n.2, jun./dez. 2018. 


\section{REFERÊNCIAS}

BRIGGS-GOODE, A. Design de estamparia têxtil. Porto Alegre: BookMan, 2014.

CASTRO, E.M. de M.e. Introdução ao desenho têxtil. Lisboa: Editorial Presença, 1981.

COSTA, M. I. Transformação do não tecido: uma contribuição do design têxtil em produtos de moda. Florianópolis. 2003. Dissertação de Mestrado, Programa de PósGraduação em Engenharia de Produção - UFSC.

EDWARDS, C. Como compreender design têxtil: guia rápido para entender estampas e padronagens. 1.ed. São Paulo: Editora SENAC, 2012.

PEZZOLO, D. B. Tecidos: história, tramas, tipos e usos. São Paulo: Editora

RUBIM, R. Desenhando a superfície. SENAC. 2009. São Paulo: Rosari, 2004.

RÜTHSCHILling, E. A. Design de superfície. Porto Alegre: Ed. da UFRGS, 2008.

TJABBES, P. O mundo mágico de Escher. São Paulo: Ed. Centro Cultural Banco do Brasil, 2011.

VINCENT-RICARD, F. As espirais da moda. Rio de Janeiro: Paz e Terra, 1987. 